\title{
Humanização do discurso em fotografias de entrevista: análise crítica de publicações do SP invisível
}

\author{
Humanization of Discourse in Interview Photographs: \\ Critical Analysis of SP invisível's Publications
}

Marcelo De Franceschi dos Santos ${ }^{1}$

\begin{abstract}
Resumo: Este artigo analisa a proposta de humanização do discurso das fotografias de entrevista do coletivo fotográfico SP invisível. Por meio da abordagem da Gramática do Design Visual, verificam-se os recursos de interação nas imagens e as características essenciais humanas nas legendas. Conclui-se que a humanização do discurso dos retratados ocorre parcialmente, sendo mais uma sensibilização orientada para os usuários do site de rede social do que para as pessoas em situação de rua.
\end{abstract}

Palavras-chave: Fotojornalismo; Humanização; Coletivo fotográfico; Gramática do design visual; Fotografias de entrevistas.

Abstract: This article analyzes the proposal to humanize the discourse of the photographic collective SP invisivel's interview photographs. Through the Grammar of Visual Design approach, the interaction resources in the images and the essential human characteristics in the captions are verified. It is concluded that the humanization of the portrayed's discourse occurs partially, being more a sensitization oriented to users of the social network site than to people in street situation.

Keywords: Photojournalism; Humanization; Photographic collective; Grammar of visual design; Interview photographs.

\section{Introdução}

A busca por humanização tem sido uma preocupação em diferentes áreas do conhecimento. Não é diferente no Jornalismo, em que a intenção de humanizar o discurso sobre pessoas é empreendida direta e eventualmente por jornais tradicionais, bem como algumas iniciativas independentes que se dedicam integralmente a tal meta. Compreendendo a humanização conforme Freire (2016) e com três características essenciais humanas (MÁRKUS, 2015), o objetivo deste artigo é analisar a proposta de humanização de discurso de um desses projetos alternativos, o coletivo fotográfico $S P$ invisível, por meio de fotografias de entrevista publicadas em site de rede social. $\mathrm{Na}$ página do Facebook do agrupamento, ele se autodescreve como "um movimento de

\footnotetext{
${ }^{1}$ Mestre em Jornalismo pela Universidade Federal de Santa Catarina (UFSC).

E-mail:mfjornalss@gmail.com
} 
conscientização e humanização através das histórias dos invisíveis da cidade de São Paulo".

O SP invisível trata-se de um grupo de profissionais que produzem a página voltada principalmente para a publicação de fotografias de entrevistas com pessoas em situação de rua na cidade de São Paulo. As fotos acompanhadas de um texto entre aspas, atribuído ao retratado, são publicadas sem qualquer menção à autoria da fotografia. Assim, a organização dos responsáveis pela página no site de rede social foi tomada como um coletivo fotográfico (SANTOS, 2020b), pois os integrantes dividem a responsabilidade, a produção, a edição e os resultados do projeto.

A grande audiência angariada pelas histórias do objeto empírico no Facebook chamou a atenção de alguns pesquisadores. Dois trabalhos possuem enfoques sobre as capacidades das publicações de ora representar a humanidade dos retratados (CARRARO; LEMOS, 2015), ora convocar os leitores a reparar nas pessoas (LOBATO, 2017). Este último constata que a página busca ressaltar a humanidade nas narrativas e fazer com que o restante da sociedade, pelo menos a parcela com acesso ao site da rede social, possa conceber as pessoas em situação de rua como seres humanos e não como objetos. O trabalho de Lobato (2017) é o único que analisa, mesmo sem método declarado, a fotografia e o texto da iniciativa. O restante ou se atém à fotografia ou à legenda, isto é, não examina integralmente as fotografias de entrevista cujo "centro do diálogo, o jornalístico, é a personalidade do indivíduo" (ABREU SOJO, 1998, p. 72, tradução nossa $)^{2}$. Tal diálogo, derivado de uma entrevista e incluído na legenda, pode problematizar as questões dos retratados (SANTOS, 2020a).

A compreensão do fenômeno por meio de uma abordagem que englobe os textos verbais e visuais se justifica porque o objeto empírico faz uso de fotografias jornalísticas aliadas a entrevistas concedidas pelos retratados. Por isso, a análise adequada não deve incidir somente nas fotografias, mas, sim, na relação entre as fotografias e as legendas, o que gera um discurso interdependente. Ao abordar ambas, é possível verificar se foram provocadas mudanças na forma como os indivíduos são enxergados e se enxergam.

Para alcançar esse objetivo, foi escolhido como método de análise a Gramática do Design Visual (GDV), por possibilitar alinhar as fotografias com a constatação das características essenciais humanas nas legendas através da separação dos diferentes

\footnotetext{
${ }^{2}$ Tradução nossa para: "El centro del diálogo, lo periodístico, es la personalidade del individuo".
} 
componentes das fotografias de entrevista publicadas pelo SP invisível no Facebook. Os autores da GDV, Kress e Van Leeuwen (2006), propõem essa perspectiva semiótica pela Análise Crítica do Discurso (ACD), na concepção de que o discurso se constrói com base nos significados das palavras em conjunto aos significados do conteúdo não verbal.

Num primeiro momento, desenvolvem-se considerações sobre a metodologia utilizada. Em seguida, as fotografias de entrevista são analisadas no nível da estrutura, descrevendo-se as características do que foi ou não valorizado imageticamente e, nas legendas, textualmente. Finalmente, realiza-se uma síntese crítica que depreende os significados propostos pelas mensagens.

\section{Método: Gramática do Design Visual}

Uma utilização da Gramática do Design Visual precedente foi a de Oliveira (2011), sobre as relações que fotografias podem estabelecer com a linguagem escrita em reportagens que mostravam fiéis de uma igreja evangélica brasileira. $\mathrm{O}$ autor afirma que a fotografia não é publicada apenas para comprovar a veracidade dos casos, mas, também, para incitar os leitores a uma determinada direção, despertando nestes "uma necessidade ou desejo de ter algo" (OLIVEIRA, 2011, p. 11). Aqui, levanta-se a hipótese de que, se uma fotografia e um texto podem ser usados para despertar desejos pessoais, essa linguagem verbo-visual pode igualmente oportunizar, pelo menos, considerações, sensibilização ou conscientização entre seres humanos.

Objetivando depreender as relações interativas de imagens significativas do $S P$ invisível, os recursos da GDV podem ser aplicados por tratarem das ações, feitas pelo produtor do texto visual, de aproximação ou de afastamento do representado com o observador. A perspectiva da GDV considera o produtor e o observador como Participante Interativo (PI) e o retratado como Participante Representado (PR). "Os PI são aqueles que produzem e consomem o texto; os PR são as pessoas, lugares e coisas presentes no texto" (OLIVEIRA, 2011, p. 7). Resumidamente, as ações do discurso são analisadas considerando quatro recursos: contato, distância social, perspectiva e modalidade.

O primeiro deles, conforme Kress e Van Leeuwen (2006, p. 117), ocorre pelo direcionamento da linha do olhar dos participantes representados. O contato é determinado ou não pela linha formada entre a direção do olhar do PR e do PI, e pode 
ocorrer de duas maneiras: por demanda ou oferta. Na primeira, o PR olha diretamente para o observador, convidando-o à interação e sendo sujeito do ato de olhar. Na segunda, o PR não encara o observador, sendo uma oferta de informação e se tornando um objeto de maior contemplação na imagem. A distância social diz respeito ao enquadramento fotográfico que "sugere relações sociais entre o observador e os objetos, construções e paisagens" (KRESS; VAN LEEUWEN, 2006, p. 127, tradução nossa) ${ }^{3}$. Instala-se uma relação entre o PR e o observador de maior ou menor distância com três tipos de caráter relacionados ao tipo de plano: íntimo, pessoal ou impessoal. O tipo íntimo equivale ao plano fechado e inclui a cabeça e o ombro do PR; o tipo pessoal corresponde ao plano médio e contém a cintura ou o joelho do PR; e o tipo impessoal se refere ao plano aberto, que expõe todo o corpo do PR, a distância.

O recurso da perspectiva ou poder se refere ao ângulo em que o PR é retratado, podendo ser de três maneiras: frontal, oblíquo ou vertical. Na frontal, indica que o PR é fotografado na altura dos olhos, ocasionando um envolvimento do PR com o observador; no modo oblíquo, ou seja, inclinado lateralmente, a impressão do PR sobre o observador provoca um "sentido de desprendimento da cena observada" (OLIVEIRA, 2011, p. 7); e, de forma vertical, existem as variações alto ou baixo, que assinalam diferentes relações de poder. Uma tomada de imagem na altura do olho indica uma relação de poder igualitário, uma tomada de cima indica uma relação de poder maior aos observadores, enquanto que fotografar de baixo implica uma relação de poder maior aos representados. Por último, a modalidade verifica o compartilhamento de "realidades" entre os participantes por meio da equivalência entre o que é mostrado na imagem e o que é considerado real para o observador. Ou seja, examina se há edições na fotografia e se esta é "natural" ou não. Essas quatro categorias de análise permitem interpretar os recursos fotográficos apresentados, avaliando se e como foi estabelecido um diálogo entre os participantes: representados e observadores.

Quanto aos textos, de acordo com a perspectiva dialética da análise crítica do discurso, não apenas são resultados das situações sociais imediatas, mas agem sobre elas. Para Resende (2016, p. 964), os autores dessa vertente de análise de discurso "sustentam que textos como elementos de eventos sociais têm efeitos causais". O discurso pode representar a sociedade, e transformá-la, não havendo uma única ordem discursiva vertical, ou seja, as ações não são completamente determinadas, ao mesmo

\footnotetext{
${ }^{3}$ Tradução nossa para: "suggest social relations between the viewer and objects, buildings and landscapes".
} 
tempo que não são absolutamente livres. Para a $\mathrm{ACD}$, os textos, verbais ou não, possuem um caráter mantenedor e modificador. Por isso, acarretam mudanças sociais, podendo tanto destituir como constituir os sujeitos de suas capacidades de articulação e resistência.

Cabe, então, averiguar criticamente qual a efetividade da proposta de humanização do discurso das publicações do SP invisível a partir dos recursos de interação nas fotografias e das características essenciais humanas nas legendas.

\section{Análise das publicações}

Dois movimentos de seleção das publicações foram realizados com o intuito de viabilizar o trabalho de análise. O primeiro foi o temporal, já que não seria compatível recolher as primeiras, que tiveram pouca audiência porque a página ainda não tinha se popularizado, e compará-las com aquelas do período em que o site obteve mais público. Tendo em mente essa discrepância, o período de coleta foi de 7 de novembro de 2014, data em que a página alcançou 100 mil curtidas $^{4}$, até 2 de abril de 2017 , em que a página marcava 341 mil seguidores ${ }^{5}$.

O segundo movimento metodológico foi a escolha das publicações com maior engajamento - critério esse, de acordo com Recuero (2013), como sendo aquelas postagens que receberam maior número de reações, comentários e compartilhamentos dos usuários da rede social. Para a autora, com o engajamento, os usuários "deixam de ser mera audiência e passam a ser construtores do discurso da marca também, porque replicam, comentam, discutem com os amigos e recomendam a marca ou o serviço" (RECUERO, 2013, on-line). A soma desses números pode indicar um resultado das interações entre Participantes Retratados (PR) e Participantes Interativos (PI). Alcançar um número maior de engajamento pode significar que as publicações foram mais efetivas na proposta de humanização do discurso dos retratados, sendo mais exemplares para a verificação das quatro ações da Gramática do Design Visual (KRESS; VAN LEEUWEN, 2006; OLIVEIRA, 2011) e das três características essenciais humanas -

\footnotetext{
${ }^{4}$ Índice marcado pela publicação disponível em: https://www.facebook.com/spinvisivel/photos/a.598272883590717.1073741828.598268693591136/7181 59488268722/?type=3\&theater. Acesso em: 10 jul. 2018.

${ }^{5}$ Estatística marcada pela reportagem disponível em: https://web.archive.org/web/20170903203330/http://www.istoedinheiro.com.br/uma-janela-para-ver-saopaulo-em-versao-on-line/. Acesso em: 10 jul. 2018.
} 
consciência, trabalho e sociabilidade - (MÁRKUS, 2015) nas legendas, conforme proposta de Santos (2019).

A identificação da tríade das características se faz necessária por meio da interpretação de expressões dos relatos. Para o ser humano se tornar mais consciente, Márkus (2015, p. 77) afirma que é exigida a "decomposição da situação concreta" em elementos que têm significado histórico-social. Por esse motivo, frases relacionadas à historicidade demonstram que o ser humano possui a característica da consciência por estar ciente do tempo passado das próprias condições e das futuras opções materiais. Orações sobre atividades laborais, incluindo intelectuais, podem representar a característica do trabalho, através do qual o humano modifica os objetos e é modificado por eles. E sentenças sobre parentescos, ou que demonstrem relações com outros humanos dos quais o retratado herdou ou compartilha habilidades e comportamentos, podem ser relacionadas a sociabilidade. É válido lembrar que cada uma das características não é passível de ser completamente isolada, isto é, elas estão implicadas entre si. A consciência pode se desenvolver pelo trabalho e pela sociabilidade. O trabalho pode se realizar pela sociabilidade e pela consciência. E a sociabilidade pode estar vinculada à consciência e ao trabalho. Entretanto, uma pode prevalecer sobre as outras em determinados trechos.

Após a definição dos critérios de análise, foram selecionadas três publicações com mais engajamento para a constituição do corpus da pesquisa. Começa-se a investigação de fato com um quadro que apresenta a estrutura das publicações para interpretar os recursos da fotografia, a estrutura da legenda e as características essenciais humanas.

Os diferentes componentes da primeira publicação - como fotografia, legenda e número de reações, comentários e compartilhamentos - são separados na Tabela 1. 
Tabela 1 - Publicação do dia 10 de março de $2015^{6}$

\begin{tabular}{|c|c|}
\hline COMPONENTES & DADOS \\
\hline Fotografia & \\
\hline Legenda & $\begin{array}{l}\text { “O mais difícil no Brasil é ser reconhecido como artista e não um } \\
\text { mendigo de luxo. Faço arte há } 15 \text { anos, hoje tenho 41, e todo mundo } \\
\text { acha que eu sou vagabundo. Tanto eu, Washington, como qualquer } \\
\text { artista, só quero reconhecimento pelo o que a gente faz. A gente não } \\
\text { rouba, não trafica, a gente faz arte. } \\
\text { Outro dia, às } 7 \text { da manhã, fui tomar um café com dinheiro no bolso e o } \\
\text { segurança me barrou. Tive que ensinar pra ele o grau de cultura que ele } \\
\text { tinha, o lugar que ele tava e que pra mim aquilo não era emprego, mas } \\
\text { ser pau mandado, porque, ao invés de ele estar olhando pra como quem } \\
\text { entra tá vestido, ele podia tá lendo um livro e se aprimorando. Ser } \\
\text { pobre é falta de sorte, burro é opção. } \\
\text { Tenho trabalho exposto em Tókio, Paris, no mundo todo, mas no meu } \\
\text { país eu sou só um mendigo de luxo. Ainda sou o mesmo, mesmo } \\
\text { nome, mesma dignidade, mas com vergonha de ser artista aqui no } \\
\text { Brasil, porque quem é artista hoje? É BBB. O sistema que faz nossos } \\
\text { artistas. } \\
\text { Eu não quero isso, quero somar com meu país, não quero só olhar uma } \\
\text { arvore caindo e chorar, quero cuidar do galho. Se eu não fizer minha } \\
\text { história, correr pro meu objetivo, vou ficar só questionando o governo } \\
\text { e sendo guiado pela Rede Globo. \#SPinvisivel \#SP” }\end{array}$ \\
\hline Reações & Mais de 18 mil \\
\hline Comentários & 802 \\
\hline Compartilhamentos & 6.258 \\
\hline
\end{tabular}

Até a data da coleta, a publicação teve mais de 25.060 engajamentos, divididos entre mais de 18 mil reações, 802 comentários e 6.258 compartilhamentos.

\footnotetext{
${ }^{6}$ Elaboração própria a partir da publicação disponível em: www.facebook.com/spinvisivel/photos/a.598272883590717.1073741828.598268693591136/7854918915 35481. Acesso em: 21 dez. 2017.
} 
Após a soma desses números, aplicam-se as ferramentas descritivas da GDV que levam em consideração os recursos de contato, distância social, perspectiva e modalidade. $\mathrm{O}$ olhar do $\mathrm{PR}$, que se oferece com as mãos para trás e de peito aberto, vai em direção ao PI, configurando um contato por demanda, um convite ao diálogo. O PR está enquadrado em um plano fechado que inclui os ombros e a cabeça, tornando a distância social de nível "íntimo". Nota-se que o formato horizontal da câmera foi girado para acompanhar a inclinação da cabeça e dos olhos de Washington. O ângulo da perspectiva da tomada está ao nível dos olhos, o que leva um envolvimento igualitário entre o PR e o PI. A modalidade é natural, embora tenha havido uma edição, que pode ser notada por um escurecimento maior nas bordas diagonais da imagem, para enfatizar o centro geométrico numa claridade ovalada.

Em relação à estrutura da legenda, ela se compõe por meio de quatro parágrafos. O primeiro deles, em que são apresentadas informações básicas sobre Washington com ausência do sobrenome -, inicia com uma opinião sobre o que é mais difícil no país. Os outros são uma continuação do mesmo pensamento, como um desabafo sobre situações vividas. O último parágrafo demonstra um objetivo de vida: fazer a própria história.

A característica da consciência pode ser interpretada pelas dificuldades de ser reconhecido enquanto artista e no tempo de 15 anos nesse ofício. Ele conta ainda um desentendimento ocorrido no dia anterior ao da realização da fotografia e da legenda, e logo depois diz se indignar com o fato de celebridades serem consideradas artistas. Há ainda o objetivo a ser alcançado: o de fazer a própria história autonomamente. $\mathrm{O}$ trabalho, no aspecto jurídico-legal, percebe-se na afirmação “A gente não rouba, não trafica, a gente faz arte" e na suposta circulação das exposições promovidas por ele. Essa característica permeia todo o relato, embora nenhuma amostra do trabalho dele esteja presente na imagem. Sem uma exibição do trabalho, de uma obra, não se reforça que se trata realmente de um artista. Tal reconhecimento, reclamado por ele logo no começo, fica somente a cargo dos usuários do site, que podem comentar se conhecem ou não suas artes. Nesse sentido, a fotografia perdeu a oportunidade de divulgar as criações argumentadas por Washington, o que validaria mais a profissão de artista. A sociabilidade familiar ou fraternal não se faz presente, embora haja menções a outros artistas de rua, ou seja, uma noção de pertencimento a uma classe trabalhadora.

A próxima publicação a ser analisada é a do dia 10 de abril de 2015, com os componentes separados conforme a Tabela 2 . 
Tabela 2 - Publicação do dia 10 de abril de $2015^{7}$

\begin{tabular}{|c|c|}
\hline COMPONENTES & DADOS \\
\hline Fotografia & 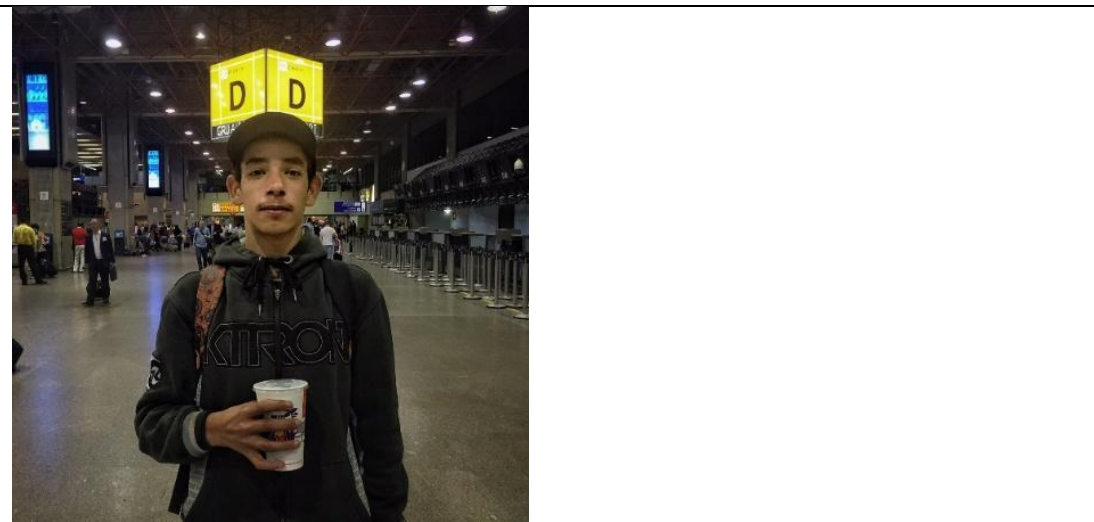 \\
\hline Legenda & $\begin{array}{l}\text { "Meu pai sumiu faz dois meses, fugiu de casa e me deixou com a } \\
\text { minha mãe e meus três irmãos, o Rodrigo, o Deivid e o recém nascido, } \\
\text { o André. Ele não faz muita falta não, bebia muito e só e enchia o saco. } \\
\text { Meu nome é Gilberto, tenho } 15 \text { anos e venho aqui pro aeroporto } \\
\text { engraxar uns sapatos depois da escola pra ajudar minha mãe em casa, } \\
\text { to na sexta serie. Ela cuida dos meus irmãos e às vezes do filho dos } \\
\text { outros pra ganhar mais um dinheirinho extra. } \\
\text { Às vezes pensam que eu vou roubar, fazer coisa errada, mas não faço } \\
\text { isso. Já tive chance de usar droga, de vender, mas prefiro ficar longe e } \\
\text { vender uma bala ou engraxar uns sapatos. Eles gostam de chamar a } \\
\text { gente pra vender porque a gente é de menor e não vai preso por muito } \\
\text { tempo, eles vão. Agora que aprovou a lei, eles vão pegar uns mais } \\
\text { novos ainda. } \\
\text { Vários entram nessa porque acham que vão ter fama, dinheiro, mas } \\
\text { também não tem outra coisa pra fazer lá onde moro. Tenho um amigo } \\
\text { que entrou nessa vida de tráfico, levou um tiro e morreu, tinha a minha } \\
\text { idade, a polícia matou enquanto ele vendia. \#SPinvisivel \#SP” }\end{array}$ \\
\hline Reações & Mais de $50 \mathrm{mil}$ \\
\hline Comentários & Mais de 1.300 \\
\hline Compartilhamentos & 9.469 \\
\hline
\end{tabular}

A segunda publicação possui cerca de 60.769 engajamentos, com mais de 50 mil reações, mais de 1.300 comentários e 9.469 compartilhamentos.

\footnotetext{
${ }^{7}$ Elaboração própria a partir da publicação disponível em: www.facebook.com/spinvisivel/photos/a.598272883590717.1073741828.598268693591136/8022519598 59474. Acesso em: 21 dez. 2017.
} 
O PR olha diretamente para o PI, formando um contato de demanda, inclusive posicionado no centro da imagem e aproveitado pela perspectiva formada pelas lâmpadas do local. Gilberto encara altivo a câmera, propondo um diálogo. O plano de enquadramento da "distância social" apresenta o PR da cintura para cima, sendo do tipo "pessoal". A perspectiva se situa um pouco abaixo da altura dos olhos, propondo uma relação equânime. A modalidade não parece ter alterações, apesar do formato mais quadrangular, correspondendo de forma "natural" ao momento da produção da foto.

A legenda tem a estrutura composta por quatro parágrafos. O primeiro traz uma situação crítica, que chama a atenção pelas informações sobre o descaso parental pelo qual ele e os irmãos passaram. O segundo parágrafo apresenta os dados básicos do retratado, como nome, idade, escolaridade e o que faz no local, além de esclarecimentos sobre a mãe dele. O terceiro parágrafo aborda como o entrevistado percebe as reações das pessoas com sua presença no espaço. A última parte traz mais impressões e lembranças dele sobre os riscos de realizar serviços ilegais.

A característica da consciência é demarcada no terceiro parágrafo, no qual são relatadas a vivência no ambiente e a opção que lhe foi dada de usar droga e trabalhar no tráfico; e no último, em que são recordadas experiências. O trabalho se evidencia no segundo parágrafo, na parte sobre os serviços de engraxate e o turno escolar. A sociabilidade é a característica mais protuberante nesse relato, com alusões à família e aos amigos, inclusive falecidos.

A estrutura da terceira publicação, realizada no dia 29 de janeiro de 2016, fica com seus diferentes componentes separados de acordo com a Tabela 3. 
Tabela 3 - Publicação do dia 29 de janeiro de $2016^{8}$

\begin{tabular}{|c|c|}
\hline COMPONENTES & DADOS \\
\hline Fotografia & \\
\hline Legenda & $\begin{array}{l}\text { "Eu estou na rua desde } 2006 \text {. Eu sou advogada, meu nome é Rosana e } \\
\text { advoguei por oito anos em São Paulo. Aí, num dado momento da } \\
\text { minha carreira sofri assédio moral dos advogados que trabalhavam } \\
\text { comigo. Não quis deixar quieto e comprei uma briga com eles, aí } \\
\text { acabou nisso que vocês tão vendo. Eles são gente poderosa. } \\
\text { Fui perseguida e vi que muitas portas se fecharam para mim, perdi meu } \\
\text { emprego e não consegui outro. Não tive apoio da minha família e nem } \\
\text { de amigos advogados. Eu acredito que estejam entregando informações } \\
\text { que questionam minha competência como profissional e como cidadã } \\
\text { por aí. } \\
\text { É mais fácil ganhar } 60 \text { reais de esmola do que você conseguir um dia } \\
\text { de trabalho, mas eu já consegui fazer faxinas em alguns prédios aqui da } \\
\text { região. Eu durmo na rua, tenho uma barraca de camping, e a Prefeitura } \\
\text { não aprova isso. Eles podem ver as pessoas dormindo ao relento, } \\
\text { enroladas em cobertores, plásticos, mas se você quer montar uma } \\
\text { barraca eles enchem o saco e tiram sua barraca. } \\
\text { Então, você vê como o Estado é algo a se pensar, em como a vida ficou } \\
\text { estúpida e como o Estado falhou. Não tem emprego pra todo mundo e } \\
\text { você vê um monte de pessoas morando na rua. Eu tento sobreviver } \\
\text { tentando trabalhar. Mas aí você olha pras essas pessoas e fica } \\
\text { imaginando o que leva cada uma a chegar nesse estado... É um } \\
\text { mistério. \#SPinvisivel \#SP - em Paraíso.” }\end{array}$ \\
\hline Reações & Mais de $85 \mathrm{mil}$ \\
\hline Comentários & Mais de 3.200 \\
\hline Compartilhamentos & 19.731 \\
\hline
\end{tabular}

${ }^{8}$ Elaboração própria a partir da publicação disponível em: www.facebook.com/spinvisivel/photos/a.598272883590717.1073741828.598268693591136/9419940625 51929. Acesso em: $21 \mathrm{dez} .2017$. 
Essa publicação teve mais de 85 mil reações, mais de 3.200 comentários e 19.731 compartilhamentos, ou seja, 107.931 engajamentos até o período da tomada. É a que possui maior engajamento de todas as selecionadas. Um fato importante é que, em um dos comentários, um usuário se solidarizou com a situação da pessoa representada, foi até ela, realizou um vídeo no qual os dois apareciam e o publicou no Facebook. ${ }^{9}$ Em compartilhamentos ou comentários, o audiovisual alcançou os familiares da mulher, que foram buscá-la. Tal consequência demonstra um resultado direto das fotografias de entrevista do SP invisível.

O contato da pessoa representada para o observador é de demanda, pois a PR olha direto para o PI. A fotografia apresenta um contato cuidadoso em apresentar a participante de forma calma para o espectador, sentada na calçada, o que propõe um diálogo. A distância social está consolidada como impessoal, em um plano aberto, que não mostra os pés da PR mas exibe parte do local. A perspectiva adotada é vertical um pouco abaixo dos olhos, o que concede uma grandeza à PR, mas, por estar num ângulo oblíquo, de tomada lateral, firma uma sensação de separação, de distanciamento do PI. A modalidade é "natural", sem vestígios de alterações, portanto a imagem passa o aspecto físico dos elementos do local, que correspondem aos do momento da foto.

Sobre a estrutura da legenda, ela é constituída por quatro parágrafos em que a depoente protagoniza a história. O primeiro pequeno conjunto de frases foi colocado para apresentar quem é, com nome e idade, e por que está na rua. Segundo Lima (2017), a pergunta "Por que você está na rua?" é uma das primeiras a serem feitas. O fato de ser uma mulher há dez anos em situação de rua se sobressai por ser um longo tempo. No terceiro parágrafo, há uma correlação do valor mencionado ( $\mathrm{R}$ \$ 60) com o preço da placa que a PR ampara na fotografia, o que responde a uma possível pergunta sobre o motivo daquele objeto. Consta uma reclamação quanto ao tratamento dado pela Prefeitura às pessoas em situação de rua. Uma conclusão de raciocínio se faz no último parágrafo, em "como o estado é algo a se pensar, em como a vida ficou estúpida e como o Estado falhou", seguida de uma incerteza sobre os motivos de todas as outras pessoas estarem na mesma situação.

A característica da consciência se nota no começo, com a possível pergunta sobre há quanto tempo a pessoa está na rua, ressaltando sua historicidade. O trecho em

\footnotetext{
${ }^{9}$ Disponível em: www.web.archive.org/web/20170720190502/http://razoesparaacreditar.com/cidadania/apos-ter-suahistoria-contada-no-sp-invisivel-advogada-reencontra-seus-familiares/. Acesso em: 10 jul. 2018.
} 
que fala da inquietação quanto a um problema demonstra responsabilidade sobre seus atos, já que se opôs a ficar calada sobre algo que considerava errado, contando as consequências sofridas. $\mathrm{O}$ trabalho está claramente na profissão de advogada e na oferta de um serviço de limpeza pelo preço mencionado. São contados mais detalhes de como é a experiência de estar na rua para aquela pessoa, com críticas à atuação da gestão do poder público. Tal trecho pode ser entendido tanto como uma cobrança por mais políticas públicas que contemplem adequadamente a população em situação de rua quanto como um comentário à política neoliberal de não interferência do Estado na criação de novos empregos públicos e de moradia. A sociabilidade é pouco destacada, havendo somente uma breve menção a família e amigos.

\section{Síntese crítica}

O corpus deste artigo consistiu em três publicações retratando dois homens e uma mulher. Nas fotografias, o tipo de contato mais empregado é o de demanda, em que os entrevistados olham diretamente para a câmera. Essa postura pode significar uma abertura ao diálogo e uma disponibilidade ao aprimoramento, além de lembrar que há uma interação entre quem segura a câmera e os sujeitos fotografados, havendo uma participação ativa destes na produção das imagens.

A distância social variou entre íntima, pessoal e impessoal. O tipo íntimo, em um plano mais fechado e sem mostrar muito o local, reforça que as outras fotografias procuram trazer um pouco do contexto da rua ocupada pelas pessoas. O pessoal não aproxima nem afasta demais quem observa a cena, o que mantém, possivelmente, uma consideração à trajetória e ao modo de vida das pessoas em situação de rua. Vale sublinhar que a publicação com mais engajamento, a terceira, teve a distância social mais estendida, em um plano aberto, que salientava o abandono da pessoa em questão. Essa diminuição do indivíduo no ambiente foi aliada à legenda em que a pessoa dizia ter ensino superior, contrastando com a baixa escolaridade da população em situação de rua (FIPE, 2015). Contrariar essa estatística, provavelmente, contribuiu para a mobilização em torno da situação dela.

A perspectiva do ângulo acompanha a direção dos olhos e da cabeça dos fotografados em duas imagens. A busca por essa linha do olhar significa que os autores não se mantêm numa posição superior, mesmo que a pessoa esteja sentada. Os representados são tratados de forma igualitária, o que reforça a tentativa de um diálogo 
entre eles e os observadores. O tipo vertical é levemente utilizado na última foto, quando se quer passar a impressão de grandiosidade, de que o retratado é merecedor de admiração por viver em meio às dificuldades econômicas e sociais.

Não se notaram grandes alterações na modalidade "natural", sendo duas imagens aparentemente sem edições. Na imagem em que houve a aplicação de um sombreamento nas bordas diagonais, a representação do local ou da pessoa não teve modificações significativas.

Quanto ao número de parágrafos, a estrutura das legendas se mantém em quatro parágrafos. Todos os textos apresentam primeiramente o nome dos entrevistados, dois deles com a idade, seguido de uma abordagem sobre a situação deles. Pode-se considerar que se trata de uma edição da retextualização (MARCUSCHI, 2001) da entrevista para o começo do texto atender às perguntas "o que" ou "quem". Os primeiros dois textos iniciam com uma curta descrição do motivo ou da situação que levou a pessoa a estar na rua, ou seja, o "porque" ou o "como". Assim, por não se inserir explicitamente no discurso, o SP invisível coloca uma ordem nos textos retextualizados com o intuito de resumir o discurso falado e torná-lo mais rapidamente legível. A justificativa dessa ação, para Lima (2017), seria valorizar a declaração do entrevistado, pois se supõe que o leitor saiba que o texto teve como origem uma conversa. No entanto, esse esforço de encurtamento ocasiona uma homogeneidade na estrutura dos depoimentos, diminui a problematização e, consequentemente, reduz a potencial humanização do texto.

No SP invisível, a retextualização das declarações dos fotografados é realizada como se elas fossem dadas espontaneamente, quando, na realidade, foram provocadas pelos fotojornalistas. Para demonstrar uma maior problematização das circunstâncias das pessoas em situação de rua, o coletivo fotográfico poderia aproveitar o espaço da descrição das imagens da rede social, com limite de caracteres definido em 63.206 desde $2011,{ }^{10}$ e apresentar a entrevista mais estruturada, no formato pergunta-eresposta. A exposição das perguntas, além de ser mais transparente, ${ }^{11}$ poderia dar um aspecto mais verossimilhante para o encontro.

\footnotetext{
${ }^{10}$ Dado disponível em:

https://web.archive.org/web/20180611004155/https://olhardigital.com.br/noticia/facebook-agora-permitemais-de-60-mil-caracteres-em-atualizacao-de-status/22616 Acesso em: 10 jul. 2018.

${ }^{11}$ Outra ação para imbuir o texto de mais credibilidade seria disponibilizar uma hiperligação para alguma notícia, confirmando as afirmações nos conteúdos. Tal ato de apuração, segundo Lima (2017), é realizado em alguns casos, mas o resultado da checagem não é publicado para o leitor.
} 
Ressalvando que não são totalmente separadas, a predominância frequente foi a característica essencial humana da consciência em duas imagens: a sociabilidade em uma e o trabalho em menor intensidade. A consciência se manifestou por meio de lembranças, opiniões ou sonhos; a sociabilidade, pelas relações de família e de amigos; e o trabalho, pelo realce nas atividades laborais ou em seus resultados.

Não há, todavia, problematização nos assuntos relatados, presença de questionamentos que intencionem conectar as causas e condições dos sujeitos, objetos do diálogo, aos aspectos da estrutura econômica-política na qual cada um deles está inserido. Quando não se explicitam as perguntas, tanto não se levam as pessoas em situação de rua a uma problematização maior de suas histórias, como defende Freire (2015), quanto não se levam os leitores a se perguntarem o que responderiam se estivessem no lugar do entrevistado ou a refletirem sobre suas próprias histórias pessoais, potencializando ainda mais o diálogo e a problematização. Portanto, há uma incitação a mudanças pessoais e à solidariedade, como a busca pela família da advogada Rosana, contada na análise da publicação três, mas não à humanização efetiva, de tentar superar a contradição opressor-oprimido (FREIRE, 2016).

Com esse levantamento, pode-se afirmar que a proposta de humanização do discurso ocorre parcialmente, sendo mais uma sensibilização. Sem buscar evidenciar textualmente a superação da contradição opressor-oprimido, o SP invisível se mantém majoritariamente humanizado e minoritariamente humanizador.

Obviamente, fazer com que as pessoas voltem seu pensamento para suas condições é um começo. “A cognição de um indivíduo sobre sua própria humanidade (e as potencialidades históricas que se seguem) é um passo para tornar-se consciente de como se é oprimido" (FERNANDES, 2016, p. 489-490). Mas, fora isso, não se procuram explicações mais articuladas ou indagações concretas com os oprimidos, como sustenta Freire. “O importante, sobretudo, é ligar, sempre que possível, a pergunta e a resposta a ações que foram praticadas ou a ações que podem vir a ser praticadas ou refeitas" (FREIRE; FAUNDEZ, 1985, p. 49). As legendas ainda poderiam contar com o nome completo dos entrevistados, se assim o quisessem.

Mesmo não atribuindo uma dimensão sistemática, as fotografias de entrevista denunciam superficialmente alguns aspectos da desigualdade das classes sociais, como dificuldade de moradia, falta de políticas públicas, pouco investimento em educação e em saúde pública. 


\section{Considerações finais}

Este artigo buscou analisar se as imagens do coletivo fotográfico SP invisível cumprem a proposta de humanizar o discurso dos retratados. Para realizar esse objetivo, foram examinadas três imagens de maior engajamento da página por meio dos critérios da Gramática do Design Visual (KRESS; VAN LEEUWEN, 2006; OLIVEIRA, 2011), que permitem analisar os recursos de interação das fotografias e depreender as relações entre os participantes representados e interativos, e por meio das características essenciais humanas da consciência, do trabalho e da sociabilidade (MÁRKUS, 2015), tendo por horizonte a humanização, conforme Freire (2016).

Pelo corpus selecionado, verificou-se que a proposta do SP invisível produz uma sensibilização, em termos genéricos. A articulação entre as pessoas que utilizam o Facebook para se comunicar ou auxiliar os retratados, instigada pelo projeto, se dá em ações isoladas. Evidentemente, são atos necessários e urgentes, mas, ao não pautar o enfrentamento das causas da desigualdade no capitalismo e como enfrentá-las, nem falar do aprimoramento de políticas públicas, resultam em medidas paliativas fadadas a se repetir. As situações dos fotografados são brevemente levantadas, pouco permitindo o questionamento das circunstâncias sociais, econômicas e políticas que as geraram. Não aborda questões estruturais com profundidade nem problematiza os depoimentos. Ao deixar de abordar os motivos macroeconômicos, sociais e políticos que levaram os retratados a estarem naquela situação, não estimula a conscientização sobre os problemas sistemáticos que geram esse contexto social. Não basta apenas tornar visível, pois se corre o risco de tornar a precariedade ainda mais aceitável e simplificar suas causas, além de contribuir para a irresolução.

Pode se partir da cotidianidade da pessoa em situação de rua, mas é preciso não se estagnar nela e ignorar as possibilidades e os sonhos futuros. A compreensão de certas formas de comportamentos dos oprimidos, como a fatalista, oportuniza a tentativa para, com eles, superá-las. Se houver uma compreensão político-econômica por parte dos produtores e um esforço conscientizador, a permanente humanização pode ser gestada em conjunto. Uma maneira de ampliar as pautas noticiando sobre temas afins seria retratar, com alguma frequência, participantes de organizações que atuam com a população de rua e acompanhar manifestações de movimentos vinculados ao direito de moradia e à situação de rua. Com esse aumento de variedade de fontes, poderia haver discussões mais aprofundadas sobre a responsabilidade, as causas da desigualdade entre 
as classes, a organização e as políticas públicas necessárias para resolver tal questão social.

O coletivo fotográfico incentiva a consciência das pessoas em situação de rua ao retratar suas trajetórias de vida, mas não a ponto de aprofundar os motivos maiores de suas situações, o que reforçaria o "ser mais" (FREIRE, 2016) dos homens e das mulheres. Para humanizar o discurso, o diálogo requer, além da busca pelas características essenciais humanas, a problematização da realidade concreta, provocando a práxis dos entrevistados e dos leitores por meio das perguntas (SANTOS, 2019) sobre o que se quer, o que se pode e o que é necessário fazer. Para Freire, o ato de interrogar necessita ser permanentemente estimulado, porque não existem perguntas bobas nem respostas definitivas, visto que o conhecimento não é finito (FREIRE; FAUNDEZ, 1985). A pergunta, a dúvida, não pode ser reprimida ao custo de negar a busca incessante pelo conhecimento e pela reflexão - capacidade sempre social e laboral que mais nos torna humanos.

\section{Referências}

ABREU SOJO, Carlos. Los géneros periodísticos fotográficos. Barcelona: Editorial CIMS, 1998.

CARRARO, Renata; LEMOS, Jaqueline. Histórias de vida em narrativas jornalísticas: o caso dos projetos Fale com Estranhos, Humanos de São Paulo e SP Invisível. In: Anais do I

Simpósio Internacional Comunicação e Cultura: aproximações com a memória e a história oral, v. 1. p. 93-104. São Caetano do Sul, 2015.

FERNANDES, Sabrina da Fonseca Borges. Pedagogia crítica como práxis marxista humanista: perspectivas sobre solidariedade, opressão e revolução. Educação \& Sociedade (Impresso), v. 37, p. 481-496, 2016.

FIPE - Fundação Instituto de Pesquisas Econômicas. Pesquisa censitária da população em situação de rua, caracterização socioeconômica da população adulta em situação de rua e relatório temático de identificação das necessidades desta população na cidade de São Paulo - Sumário Executivo. São Paulo: FIPE, 2015.

FREIRE, Paulo; FAUNDEZ, Antonio. Por uma pedagogia da pergunta. 5. ed. Rio de Janeiro: Paz e Terra, 1985.

FREIRE, Paulo. Pedagogia do oprimido. 40. ed. Rio de Janeiro: Paz e Terra, 2016.

KRESS, Gunther; VAN LEEUWEN, Theo. Reading Images: a Grammar of Visual Design. Londres: Routledge, 2006.

LIMA, Vinicius. Entrevista [10 nov. 2017]. Entrevistador: Marcelo De Franceschi dos Santos. São Paulo, 2017, 1 arquivo em mp3 (86 min). 
LOBATO, Mayara. Vozes, memórias e imagens da exclusão social: um estudo sobre as narrativas da página SP Invisível. In: Anais do XI Encontro de Pesquisadores em

Comunicação e Cultura, v. 1. p. 45-60. Comunicação e Literatura. Sorocaba: Uniso, 2017.

MARCUSCHI, Luiz Antonio. Da fala para a escrita: atividades de retextualização. 2. ed. São Paulo: Cortez, 2001.

MÁRKUS, György. Marxismo e antropologia: o conceito de essência humana na filosofia de Marx. São Paulo: Expressão Popular, 2015.

OLIVEIRA, Derli Machado de. Gênero do discurso/textual e multimodalidade: análise crítica dos testemunhos publicados na folha universal. In: Anais do VI Simpósio Internacional de Estudos de Gêneros Textuais. Natal, 2011.

RECUERO, Raquel. Engajamento x Audiência no Facebook: Uma breve discussão. On-line, 2013. Disponível em: http://www.raquelrecuero.com/arquivos/2013/03/engajamento-xaudiencia-no-facebook.html. Acesso em: 10 jul. 2018.

RESENDE, Viviane de Melo. Representação de pessoas em situação de rua no jornalismo online: quais são as vozes convocadas para falar sobre a situação de rua? Revista de Estudos da Linguagem, v. 26, p. 955-988, 2016.

SANTOS, Marcelo De Franceschi dos Santos. Do jornalismo humanizado ao fotojornalismo humanizador com perspectiva de humanismo marxista. Razón y Palabra, v. 23, p. 435-457, 2019.

. O diálogo como concepção para a entrevista jornalística retextualizada na legenda fotográfica. Revista Alterjor, v. 21, p. 97-120, 2020a.

. Os coletivos fotográficos e a prática do fotojornalismo publicada em sites de redes sociais. Revista Temática (UFPB), v. 16, p. 93-108, 2020 b. 